\title{
Determination of Caffeine in Coffee Samples by High Performance Liquid Chromatography and Ultra Violet - Visible Spectrophotometry Methods from Wollega, Ethiopia
}

\author{
Shibiru Eticha, Tesfa Bedassa \\ Department of Chemistry, Wollega University, Nekemte, Ethiopia \\ Email address: \\ shibeticha52@gmail.com (S. Eticha)
}

To cite this article:

Shibiru Eticha, Tesfa Bedassa. Determination of Caffeine in Coffee Samples by High Performance Liquid Chromatography and Ultra Violet Visible Spectrophotometry Methods from Wollega, Ethiopia. International Journal of Biochemistry, Biophysics \& Molecular Biology.

Vol. 5, No. 1, 2020, pp. 8-17. doi: 10.11648/j.ijbbmb.20200501.12

Received: May 15, 2020; Accepted: June 1, 2020; Published: August 27, 2020

\begin{abstract}
In this research caffeine content in coffee sample from Abe Dongoro, Sasiga, Gida Ayana and Sibu Sire of Wollega administrative zone of Ethiopia were determined using High Performance Liquid Chromatography (HPLC) and UVVis Spectrophotometry methods. Caffeine in aqueous extract of coffee samples was extracted with dichloromethane prior to analysis by UV-Vis spectrophotometry method and dichloromethane was evaporated from the extract and the extract was dissolved in water (HPLC grade) to determine caffeine contents in coffee samples using HPLC method. The linearity of the HPLC and UV-Vis spectrophotometry methods were $\mathrm{R}^{2}=0.9999$ and $\mathrm{R}^{2}=0.9997$ respectively. HPLC and UV-Vis spectrophotometry methods were found to be accurate with recoveries of $97.5 \%$ and $117.4 \%$, respectively. Limits of detection (LOD) obtained were $0.148 \mathrm{mg} / \mathrm{L}$ for HPLC method and $0.284 \mathrm{mg} / \mathrm{L}$ for UV-Vis spectrophotometric method. The caffeine contents in coffee samples obtained using UV-Vis spectrophotometry method was 3.42, 2.638, 2.207 and $2.986 \mathrm{mg} / \mathrm{L}$ for Abe Dongoro, Gida Ayana, Sasiga and Sibu Sire coffee samples respectively. Similarly, using HPLC method the caffeine contents in coffee samples obtained was 1.871, 1.601, 1.307, $1.83 \mathrm{mg} / \mathrm{L}$ for Abe Dongoro, Gida Ayana, Sasiga and Sibu Sire coffee samples. There is a significant difference between the caffeine contents in coffee samples obtained by the two methods.
\end{abstract}

Keywords: Coffee Samples, Caffeine, UV-Vis Spectrophotometry, High Performance Liquid Chromatography, Horro Guduru Wollega, East Wollega

\section{Introduction}

Coffee is one of the popular beverages that is widely used around the world due to its pleasant flavor, aroma and fitness benefits. Botanically it belongs to genus Coffea in the Rubiaceae family. Genus Coffea contains over 80 diverse numbers of species. However, Coffea arabica and Coffea robusta are the main genus Coffea species [1]. Arabica coffee is grown-up in about tropical and sub-tropical of 80 countries. Ethiopia is among these countries, which heavily depend on coffee exports for foreign exchange earnings [2].

Coffee has a complex mixture of chemical constituents such as phenolic compounds, caffeine, trigonelline, chlorogenic acids, protein, lipids and minerals [3-5]. The chemical content of coffee varies with species, geographical source, climatic parameters, cultivation system (organic versus conventional system) [6].

Caffeine is a natural alkaloid widely used in food industry as a psycho stimulant in beverages and foods for information processing and cognitive performance [7]. It is found in tea [8], chocolate [9], caffienated, decaffienated beverages and energy drinks [10], Arabica coffee [11] and Robusta coffee [12].

Caffeine is used to increases alertness, improves shortterm memory and increases the efficiency of certain drugs.

However, over dose use of caffeine is a matter of health concerns such as gastric acid secretion and higher risk of miscarriage [13]. Therefore, monitoring of caffeine content in food and beverages is an important challenge of food quality control.

Various analytical and electro analytical techniques such as high performance liquid chromatography [14, 15], Fourier 
transforms near infrared reflectance spectroscopy [16], UVVis spectrophotometery [17, 18] and voltammetry [19] are reported for the determination of caffeine contents in food and beverages.

Caffeine contents in coffee samples grown at different part of Ethiopia were studied using several analytical techniques. However, to this date, there is no published research finding that made use of Ultra Violet-Visible Spectrophotometery (UV-Vis) and High Performance Liquid Chromatography (HPLC) for the determination of the caffeine contents in coffee samples from Eastern and Horro Guduru Wollega Zones in the Western part of Ethiopia. Therefore, the objective of this study was to determine caffeine in coffee samples from Abe-Dongoro, Sasiga, Gida-Ayana and SibuSire districts in Wollega zones of Western Ethiopia by High Performance Liquid Chromatography (HPLC) and Ultra Violet-Visible Spectrophotometery (UV-Vis) methods.

\section{Experimental}

\subsection{Study Area}

Coffee bean samples were collected from three selected districts of Eastern Wollega administrative zone from the Sasiga, Gida-Ayana, Sibu-Sire and Abe-Dongoro district of Horro- Guduru Wollega administrative zone directly from the farmers' farmlands. The geographical maps of the sampling sites were displayed in Figure 1. The districts were preferred purposely as they are major coffee producing parts of the administrative zone.

\subsection{Chemicals and Reagents}

Chemicals and reagents used were of analytical grade; standard caffeine powder (Aldrich, Germany), HPLC grade methanol (Aldrich, Germany), HPLC grade water and dichloromethane (Aldrich, Germany).

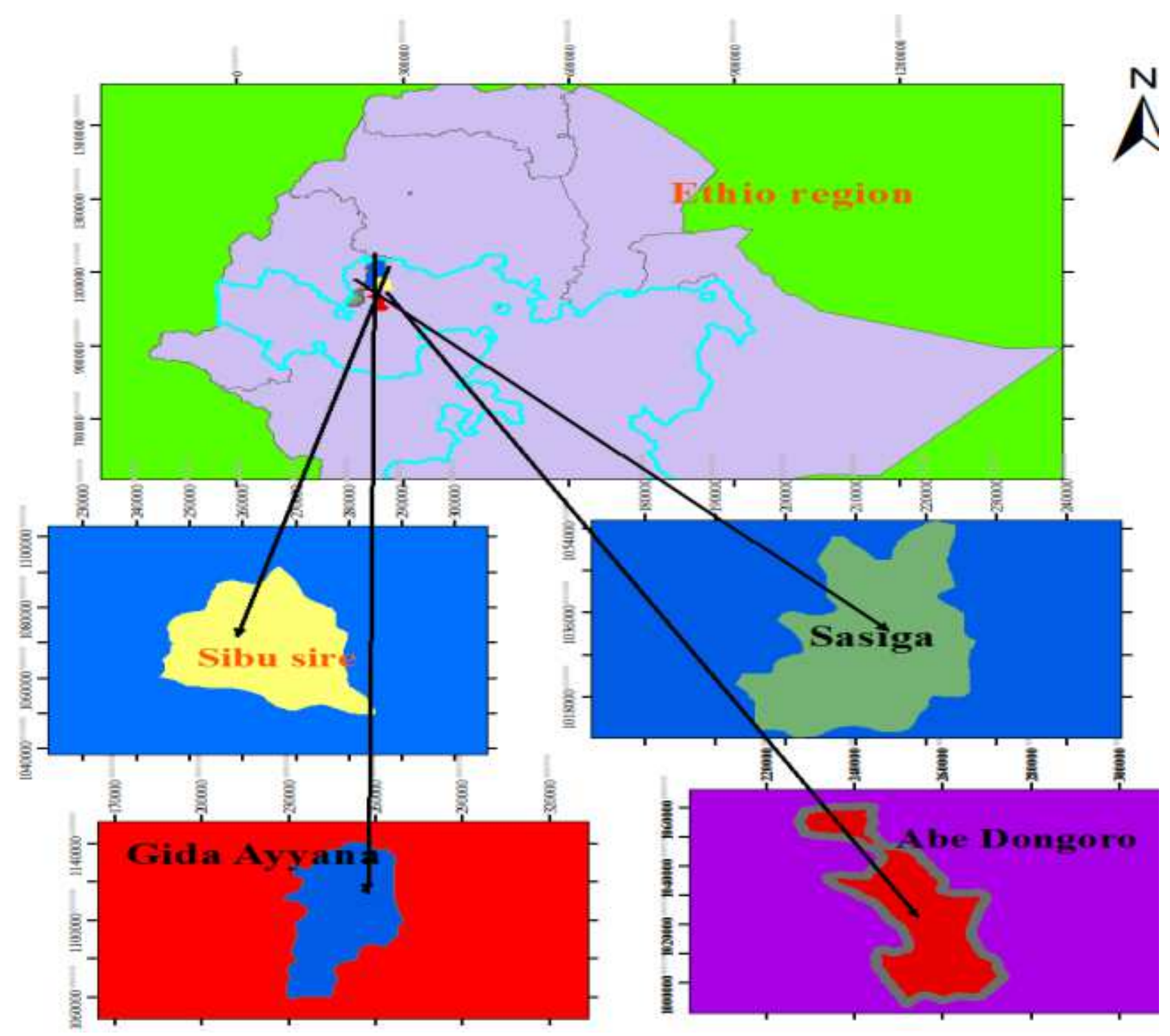

Figure 1. Geographical location of sampling site. 


\subsection{Instruments}

Caffeine contents in coffee samples was determined using UV-Vis spectrophotometry (18- 1884-01-0076, spectral bandwidth $2.00 \mathrm{~nm}$ ) and HPLC system (Agilent1260, Germany) equipped with a pump (G1310B), column (G1316A/ Agilent poroshell-C ${ }_{18}(4.6 \times 250 \mathrm{~mm}, 2.7 \mu \mathrm{m})$ ), auto sampler (G1329B), variable wavelength detector (G4286B) and Chemistation software.

\subsection{Preparation of Standard Solutions}

For analysis by HPLC, the stock solution of standard caffeine $(1000 \mathrm{mg} / \mathrm{L})$ was prepared by dissolving $100 \mathrm{mg}$ of standard caffeine in $50 \mathrm{~mL}$ warm, ultrapure water in $100 \mathrm{~mL}$ of volumetric flask and filled to the final volume with ultrapure water. Intermediate standard solution of caffeine $(100 \mathrm{mg} / \mathrm{L})$ was prepared from the stock solution. Finally, concentrations of 2, 4, 8 and $16 \mathrm{mg} / \mathrm{L}$ caffeine solution were used to construct calibration curve.

For the UV-Vis spectrophotometric analysis, the stock solution of standard caffeine $(1000 \mathrm{mg} / \mathrm{L})$ was prepared by dissolving $100 \mathrm{mg}$ of standard caffeine in $50 \mathrm{~mL}$ dichloromethane in $100 \mathrm{~mL}$ of volumetric flask and filled to the final volume with dichloromethane. Intermediate standard solution of caffeine $(100 \mathrm{mg} / \mathrm{L})$ was prepared by diluting the stock solution with dichloromethane. Finally concentrations of $0,2,4,8$ and $16 \mathrm{mg} / \mathrm{L}$ were prepared by diluting the working standard for calibration. For the quantitative determination of caffeine contents in coffee samples the $\lambda_{\max }(272 \mathrm{~nm})$ of caffeine standard was selected from the reported literature, this is because of the characteristics observed peak of caffeine at 271-276 nm [20, 21].

\subsection{Coffee Sample Preparation}

A $20 \mathrm{~g}$ of coffee bean from each sample was roasted by using the conventional coffee roasting machine. After roasting, the coffee bean samples were cooled at room temperature. Each of the roasted and cooled coffee bean samples was grounded and homogenized using an electric coffee grinder machine. After that, each of the coffee powder was screened through $300 \mu \mathrm{m}$ sieve to get a uniform mixture and kept in plastic bag at room temperature until it is used for the extraction. The extraction of caffeine from the aqueous solution into dichloromethane was carried out by the reported methods [22, 23].

Trigonelline, chlorogenic and caffeic acids are the primary interference in the quantitative determination of caffeine in coffee samples using UV-Vis spectrophotometry method. In order to overcome this difficulty the coffee samples was first dissolved in water and then the caffeine was extracted from the aqueous extract using dichloromethane. The efficiency of dichloromethane to extract caffeine from coffee beans is 98 $99 \%$ [23]. For HPLC analysis, $2 \mathrm{~mL}$ aliquot from dichloromethane extract was pipetted into test tube and the dichloromethane was evaporated; the residue was dissolved in $2 \mathrm{~mL} \mathrm{HPLC}$ grade water.

\subsection{Chromatographic Analysis}

The samples and standard solutions of $20 \mu \mathrm{L}$ were injected into the column with a flow rate of $0.8 \mathrm{~mL} / \mathrm{min}$ using a mobile phase consisting of water and methanol $(75: 25, \mathrm{~V} / \mathrm{V})$. The column temperature was kept at $30{ }^{\circ} \mathrm{C}$ and data rate at $10 \mathrm{~Hz}$. Chromatographic data for caffeine were collected at $272 \mathrm{~nm}$.

\subsection{Method Validation}

Linearity of the calibration curves was evaluated based on the magnitude of the regression coefficient $\left(R^{2}\right)$. Accuracy was validated by using spike-recovery method. The limit of detection (LOD) and limit of quantification (LOQ) of the analytical method is obtained based on the standard deviation of response and slope of the calibration curve [24]. In this study, LOD and LOQ of the methods were calculated as $\mathrm{LOD}=3.3 \sigma / \mathrm{s} ; \mathrm{LOQ}=10 \sigma / \mathrm{s}$, were, $\mathrm{s}$ is the slope of the calibration curve and $\sigma$ is the standard deviation of the yintercept of the regression line. Differences between groups were assessed by one-way analysis of variance (ANOVA). The results with $\mathrm{P}<0.05$ were regarded to be statistically significant.

\section{Result and Discussion}

\subsection{Analytical Performance Characteristics}

The performance parameters for both HPLC and UV-Vis spectroscopic analysis are presented in Table 1. The calibration curve for both of the analysis methods showed an excellent linear fit. LOD for HPLC and UV-Vis methods were 0.148 and $0.284 \mathrm{mg} / \mathrm{L}$, respectively. Recoveries of both methods were satisfactory. Thus, the proposed methods were appropriate for determination of caffeine contents in coffee samples.

Table 1. Performance parameters of the HPLC and UV-Vis spectrophotometry methods.

\begin{tabular}{llll}
\hline No & Parameters & HPLC method & UV-Vis method \\
\hline 1 & Coefficient of correlation & 0.9999 & 0.9997 \\
2 & LOD $(\mathrm{mg} / \mathrm{L})$ & 0.148 & 0.284 \\
3 & LOQ $(\mathrm{mg} / \mathrm{L})$ & 0.449 & 0.86 \\
4 & Recovery & $97.5 \%$ & $117.4 \%$ \\
\hline
\end{tabular}

\subsection{Quantity of Caffeine in Coffee Samples}

The identity of the analyte was determined by comparing the retention time extracted from the coffee samples with retention time of standard caffeine. Under the optimized experimental condition, the retention time of caffeine obtained was 10.6 minutes. In addition, the identity of caffeine was confirmed by spiking one of the coffee extract with standard caffeine. An increase in peak area after caffeine standard addition to the coffee extract supported the identification of the caffeine extracted from the samples. The extracts of the coffee samples were analyzed using HPLC method to determine the caffeine contents in the samples (Table 2). 
Table 2. Caffeine content in coffee samples obtained using HPLC method.

\begin{tabular}{lllll}
\hline Coffee samples & Retention time & Peak area & Concentration $(\mathbf{m g} / \mathbf{L})$ & \% of Caffeine (w/w) \\
\hline Abe Dongoro & 10.649 & 179.856 & 1.871 & 1.12 \\
Gida Ayana & 10.627 & 156.336 & 1.601 & 0.96 \\
Sasiga & 10.637 & 130.671 & 1.307 & 0.78 \\
Sibu Sire & 10.637 & 176.324 & 1.830 & 1.1 \\
Sasiga (duplicated) & 10.616 & 130.157 & 1.301 & 0.78 \\
Gida Ayana (4000 $\mathrm{mg}$ spiked) & 10.490 & 212.578 & 2.246 & 1.35 \\
\hline
\end{tabular}

The caffeine content in coffee samples obtained using HPLC method was in the range of $0.78-1.12 \%(w / w)$. The highest caffeine content was obtained in the Abe Dongoro coffee sample which gave a concentration of $1.871 \mathrm{mg} / \mathrm{L}$ or $1.12 \%(\mathrm{w} / \mathrm{w})$, followed by a Sibu Sire coffee sample which gave a concentration of $1.830 \mathrm{mg} / \mathrm{L}$ or $1.10 \%(\mathrm{w} / \mathrm{w})$. The least caffeine content was obtained in Sasiga coffee sample which gave a concentration of $1.307 \mathrm{mg} / \mathrm{L}$ or $0.78 \%(\mathrm{w} / \mathrm{w})$ (Table 2). The results of the present study are comparable with the results reported in the literature $0.06-2.55 \%(\mathrm{w} / \mathrm{w})$ [25], 0.84-1.15\% (w/w) [26] and 0.8-1.4\% (w/w) [27] for caffeine in coffee samples.

The absorbance of the caffeine in each coffee sample solution was measured using UV-Vis spectrophotometry at $272 \mathrm{~nm}$ against the corresponding blank (dichloromethane). Caffeine content in coffee samples obtained by UV-Vis spectrophotometry method was presented in Table 3.

Table 3. Caffeine content in coffee samples obtained by UV-Vis spectrophotometry method.

\begin{tabular}{lll}
\hline Coffee samples & Conc. $(\mathbf{m g} / \mathbf{L})(\mathbf{m e a n} \pm \mathbf{s d})$ & \% of Caf $(\mathbf{w} / \mathbf{w})(\mathbf{m e a n} \pm \mathbf{s d})$ \\
\hline Abe Dongoro & $3.420 \pm 0.059$ & $2.052 \pm 0.036$ \\
Gida Ayana & $2.638 \pm 0.026$ & $1.583 \pm 0.015$ \\
Sasiga & $2.207 \pm 0.009$ & $1.322 \pm 0.005$ \\
Sibu Sire & $2.986 \pm 0.016$ & $1.792 \pm 0.01$ \\
Gida Ayana (4000 mg spiked) & $3.420 \pm 0.076$ & $2.052 \pm 0.046$ \\
\hline
\end{tabular}

The highest caffeine content was obtained in the Abe Dongoro coffee sample which gave a concentration of 3.420 $\mathrm{mg} / \mathrm{L}$ or $2.052 \%(\mathrm{w} / \mathrm{w})$, followed by a Sibu Sire coffee sample which gave a concentration of $2.986 \mathrm{mg} / \mathrm{L}$ or $1.792 \%$ $(\mathrm{w} / \mathrm{w})$. The least caffeine content was obtained in Sasiga coffee sample which gave a concentration of $2.207 \mathrm{mg} / \mathrm{L}$ or $1.322 \%(\mathrm{w} / \mathrm{w})$.

The caffeine content in coffee samples obtained using UVVis spectrophotometry method was in the range of 1.322 $2.052 \%(w / w)$. There was a significant difference $(\mathrm{p}<0.05)$ in caffeine contents among all the coffee samples. The results of the present study are comparable with the caffeine contents reported in the literature $0.9-3.01 \%(w / w)[21]$, $1.24-2.54 \%(\mathrm{w} / \mathrm{w})[28]$ for caffeine in coffee samples.

The caffeine content in coffee samples obtained using UVVis spectrophotometry method was compared with the caffeine content in coffee samples obtained using HPLC method (Table 4). In contrast to this, the UV-Vis spectrophotometry method is much faster than the HPLC method. The caffeine contents in coffee samples were found in the range of $1.322-2.052 \%(\mathrm{w} / \mathrm{w})$ using UV-Vis spectrophotometry method and $0.78-1.12 \%(\mathrm{w} / \mathrm{w})$ using HPLC method.

Table 4. Comparison of caffeine content in coffee samples\% (w/w) obtained using UV-Vis spectrophotometry and HPLC methods.

\begin{tabular}{llll}
\hline \multirow{2}{*}{ No. } & \multirow{2}{*}{ Sample name } & Method & HPLC \\
\cline { 3 - 4 } & & UV-Vis & 1.12 \\
2 & Abe Dongoro & 2.052 & 0.96 \\
2 & Gida Ayana & 1.583 & 0.78 \\
3 & Sasiga & 1.322 & 1.1 \\
\hline
\end{tabular}

The present results indicates that the caffeine contents in coffee samples obtained using UV-Vis spectrophotometry method was higher than the caffeine contents in coffee samples obtained using HPLC method.

Application of statistical analysis (paired t-test at 0.05 levels) to the data obtained by the two methods indicated that there is significant difference between them. The caffeine contents of coffee samples obtained in this study was compared with caffeine values reported for coffee samples from different parts of the Ethiopia (Table 5).

Table 5. Comparison of results of the present study with the reported literature

\begin{tabular}{llll}
\hline Method & \% Caf $(\mathbf{w} / \mathbf{w})$ & Origin of coffee & References \\
\hline UV-Vis & $0.97-1.53(\mathrm{n}=4)$ & North West Ethiopia & Belete Tewabe \& Solomon Libsu, 2015 [29] \\
UV-Vis & $0.6-0.9(\mathrm{n}=16)$ & Hararghe & Ephrem Demissie et al., 2016 [30] \\
HPLC & $0.6-1.1(\mathrm{n}=9)$ & South West Ethiopia & Mulu Hagos et al., 2018 [22] \\
HPLC & $0.62-1.99(\mathrm{n}=5)$ & Gojjam & Maria et al., 2000 [31] \\
\hline
\end{tabular}




\begin{tabular}{llll}
\hline Method & \% Caf $(\mathbf{w} / \mathbf{w})$ & Origin of coffee & References \\
\hline HPLC & $1.31-1.36(\mathrm{n}=6)$ & Bale & Legesse Adane et al., 2018 [32] \\
UV-Vis & $1.32-2.052(\mathrm{n}=4)$ & *Wollega & Present work \\
HPLC & $0.78-1.12(\mathrm{n}=4)$ & *Wollega & Present work \\
\hline
\end{tabular}

* Wollega $=$ Eastern and Horro Guduru.

The caffeine content in coffee samples reported in the present study using UV-Vis spectrophotometry method is slightly greater than the reported caffeine contents in North West Ethiopia and Hararghe coffee samples using UV-Vis spectrophotometry method and slightly greater than the reported caffeine contents of South West Ethiopia, Gojjam and Bale coffee samples using HPLC method.

The obtained caffeine content in coffee samples in this study using HPLC method is slightly smaller than caffeine contents in Gojjam coffee samples and comparable with the South West Ethiopia coffee samples reported by HPLC method and somewhat smaller than the caffeine contents in North West Ethiopia coffee samples reported using UV-Vis spectrophotometry method.

In general the caffeine contents in coffee samples obtained in the present work is in the range of caffeine contents of export standard Ethiopian coffee samples (0.46$2.82 \% \mathrm{w} / \mathrm{w})$ reported using HPLC method [31]. The difference in caffeine contents in coffee samples are due to several factors such as coffee variety, genetic properties of the cultivars, maturity of the beans at harvest, harvesting method and postharvest processing conditions (fermentation, washing, drying, storage), agricultural practices (shade, pruning, fertilization), environmental factors (soil, altitude, sun exposure), climatic parameters (rainfall, temperature), method of preparation (the brewing of coffee) and analytical methods used for the determination of caffeine in coffee samples $[6,33]$.

\section{Appendix}

Appendix A: Chromatogram of $2 \mathrm{mg} / \mathrm{L}$ of Standard Caffeine

\section{Conclusion and Recommendations}

In this study, HPLC and UV-Vis spectrophotometry methods were successfully applied for the determination of caffeine contents in coffee samples grown in Wollega from Sasiga, Gida Ayana, Sibu Sire and Abe Dongoro woredas. Variations of the caffeine contents in coffee samples were observed; these variations depend on the geographical origin of the coffee samples and the analytical methods used for caffeine content determination in coffee samples. Significant difference was observed between the caffeine value obtained by HPLC and UV-Vis spectrophotometry methods. The caffeine content in coffee samples obtained in this study is in the range of caffeine contents of export standard Ethiopian coffee samples. Further study is required in which coffee samples could be analyzed with statistically sufficient data, coffee variety, agricultural and environmental factors as well as other components of coffee beans such as chlorogenic acid, trigoneline and sucrose in coffee beans.

\section{Acknowledgements}

The authors primarily offer their deepest heart-felt thanks and glory to Almighty GOD. The authors are also acknowledge Wollega University and Ministry of Science and Higher Education for fellowships and financial support.

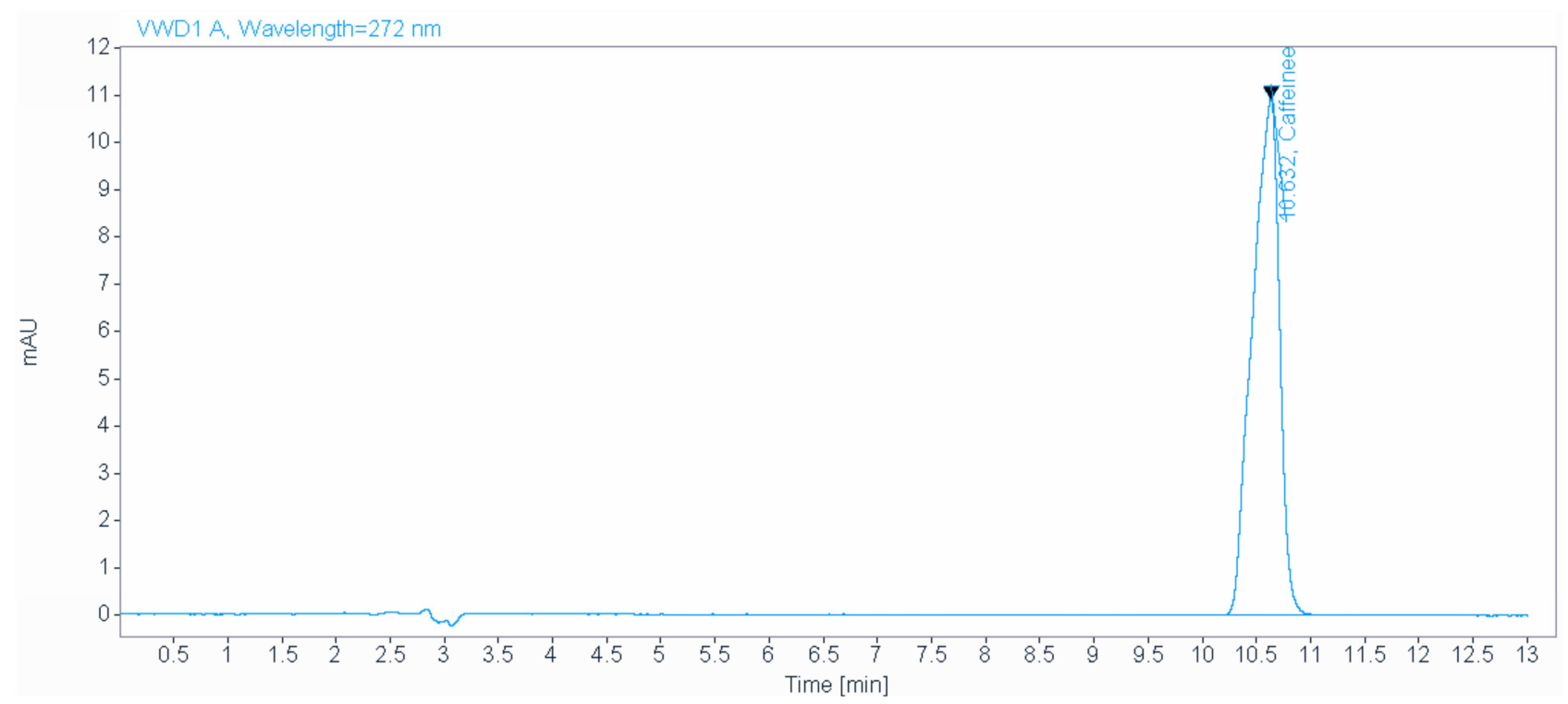


Appendix B: Chromatogram of $4 \mathrm{mg} / \mathrm{L}$ of Standard Caffeine

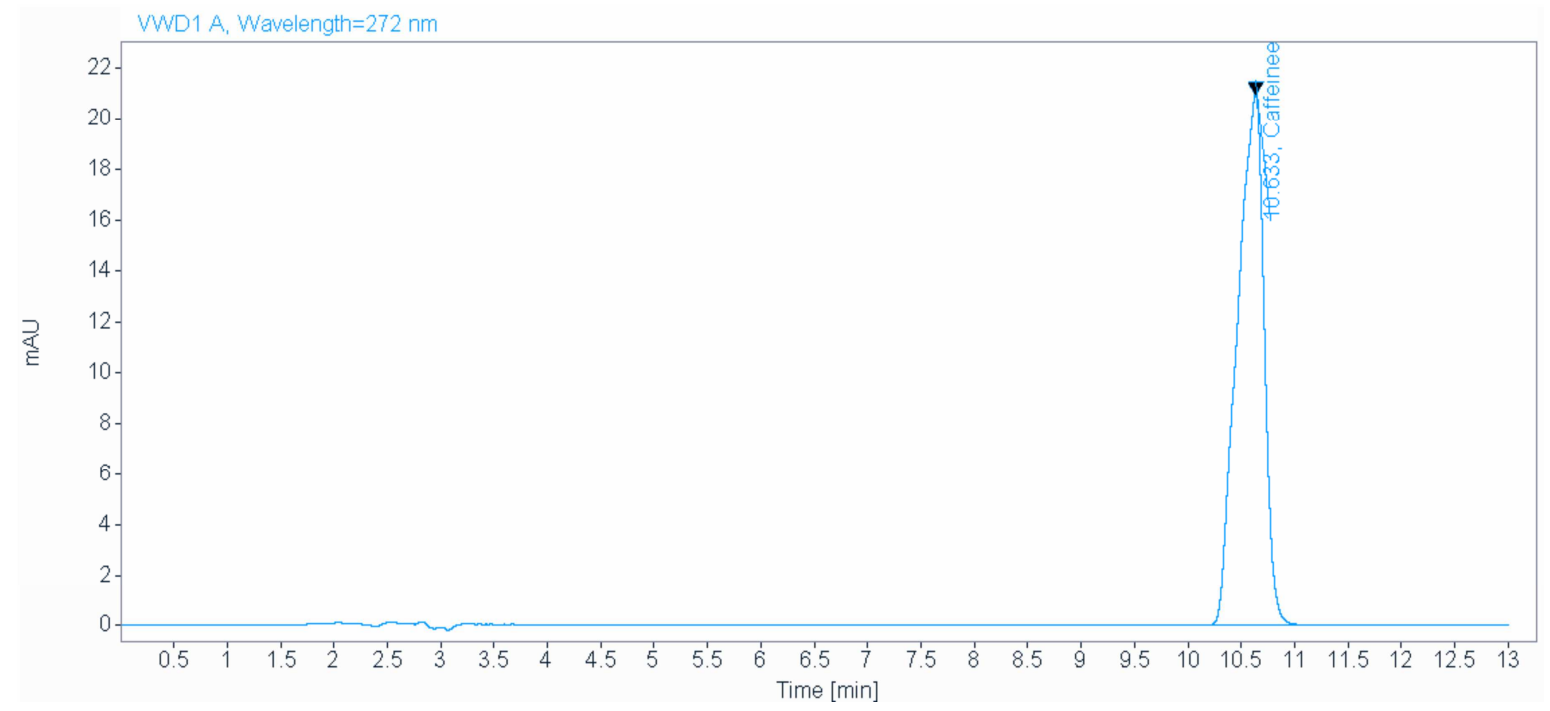

Appendix C: Chromatogram of $8 \mathrm{mg} / \mathrm{L}$ of Standard Caffeine

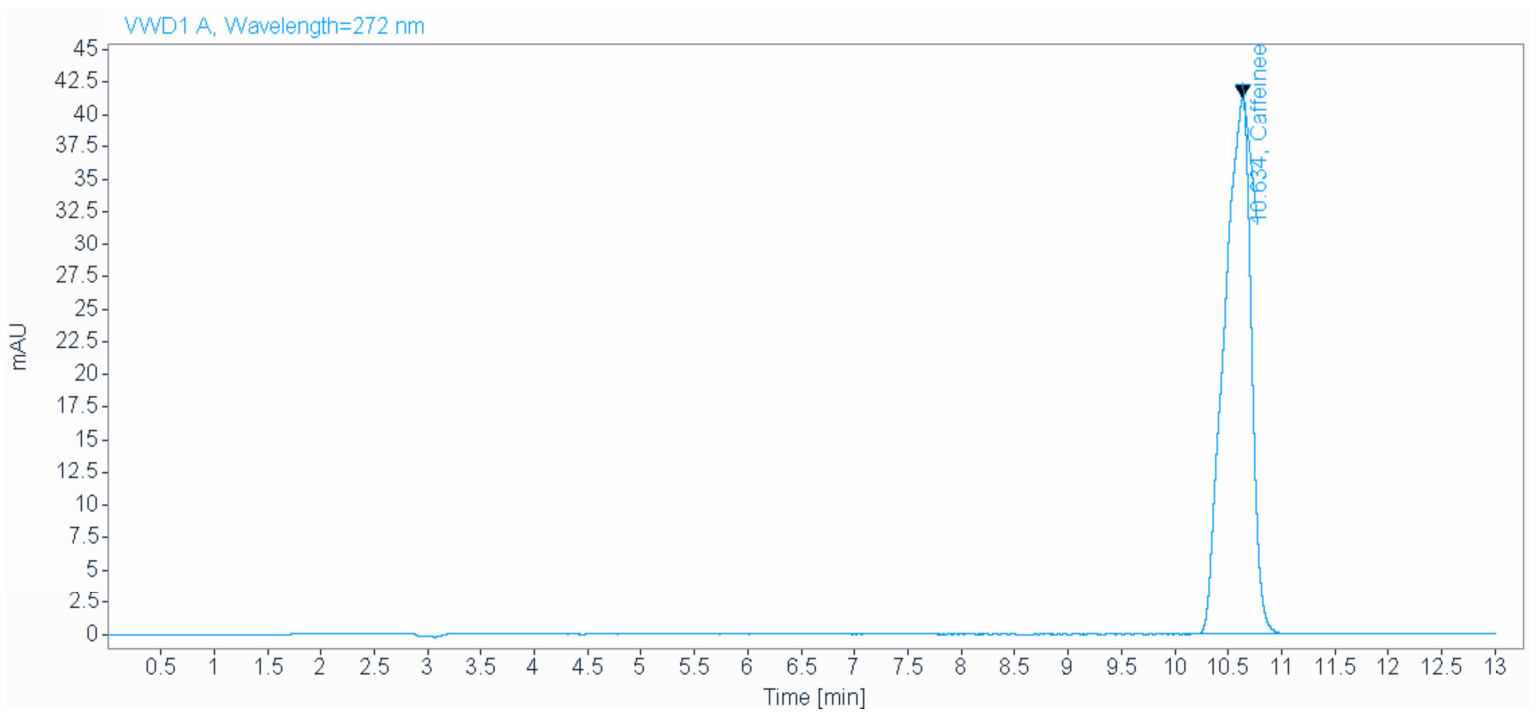

Appendix D: Chromatogram of $16 \mathrm{mg} / \mathrm{L}$ of Standard Caffeine

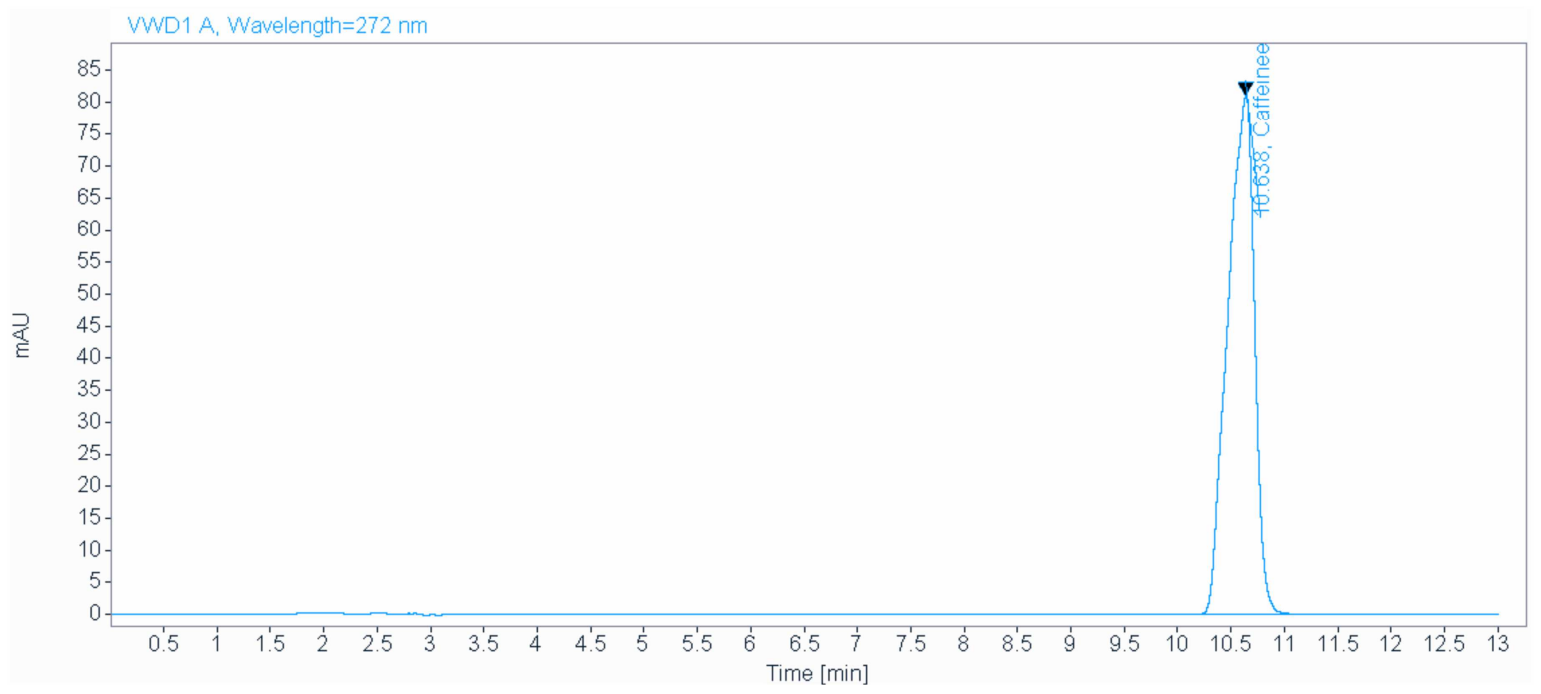




\section{Appendix E: Chromatogram of Caffeine of Abe Dongoro Coffee Sample}

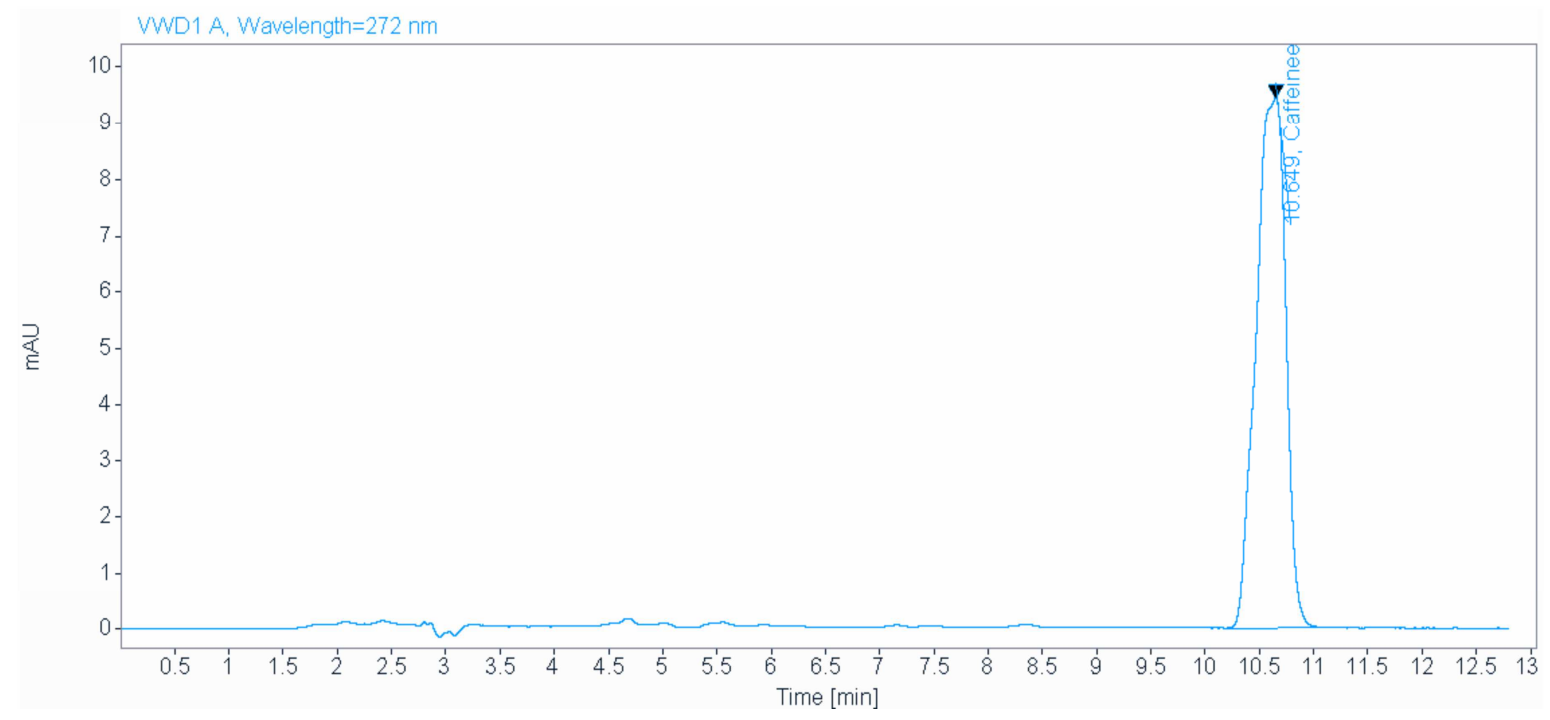

Appendix F: Chromatogram of Caffeine of Gida Ayana Coffee Sample

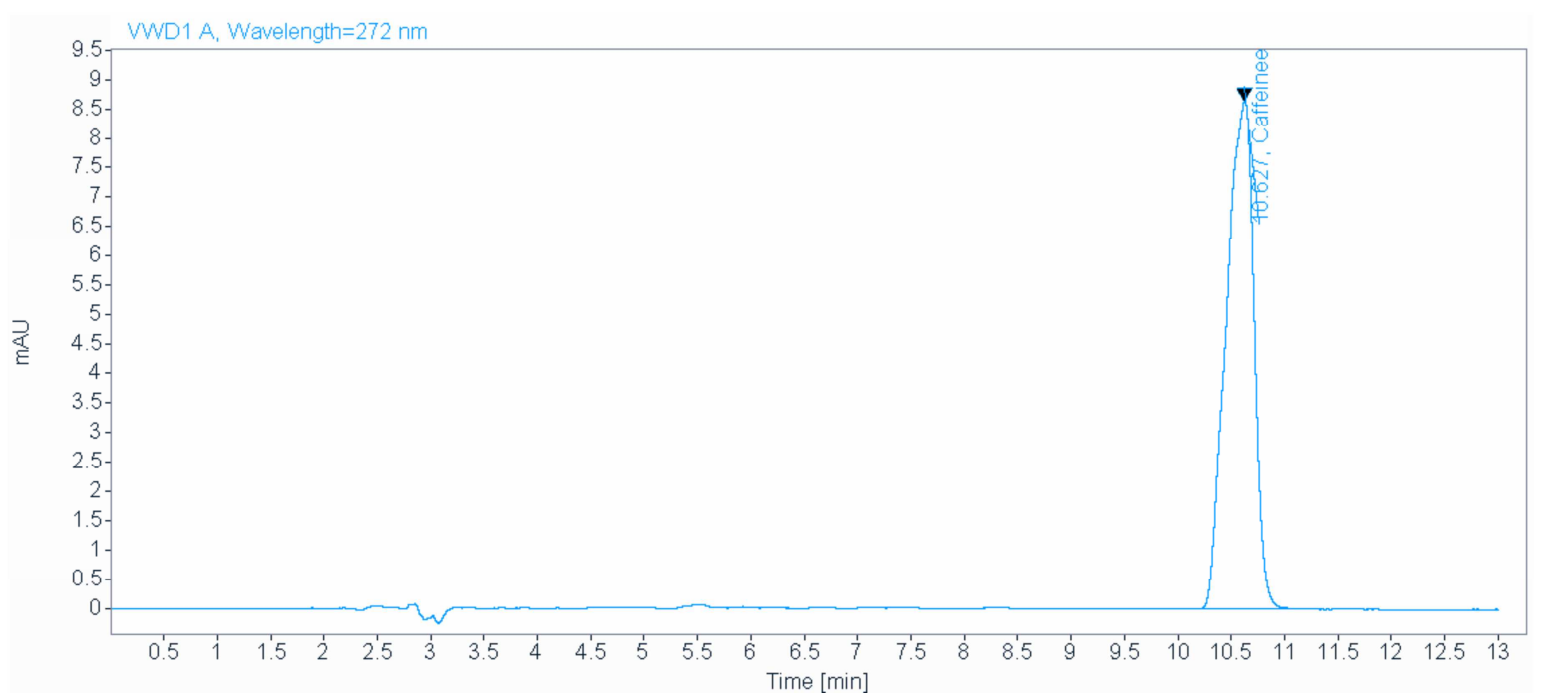

Appendix G: Chromatogram of Caffeine of Sasiga Coffee Sample

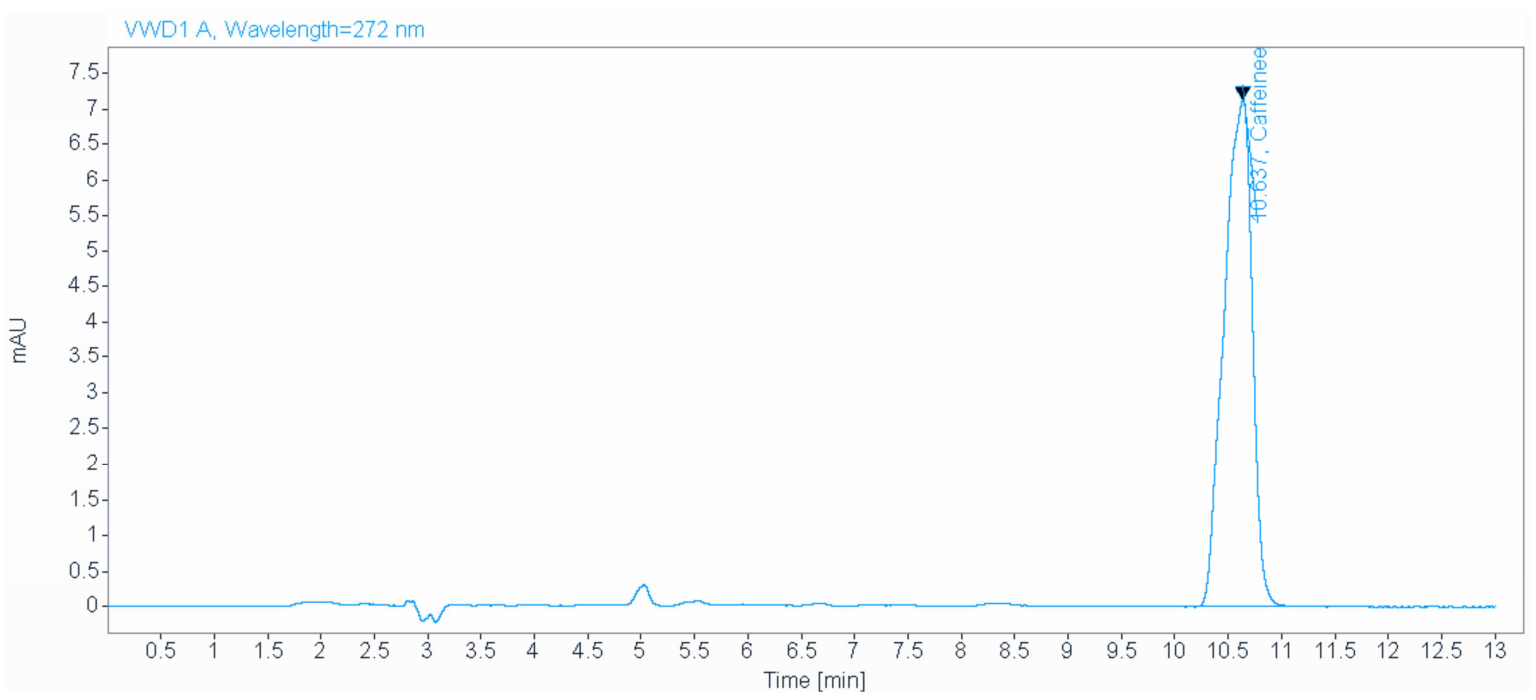


Appendix H: Chromatogram of Caffeine of Sibu Sire Coffee Sample

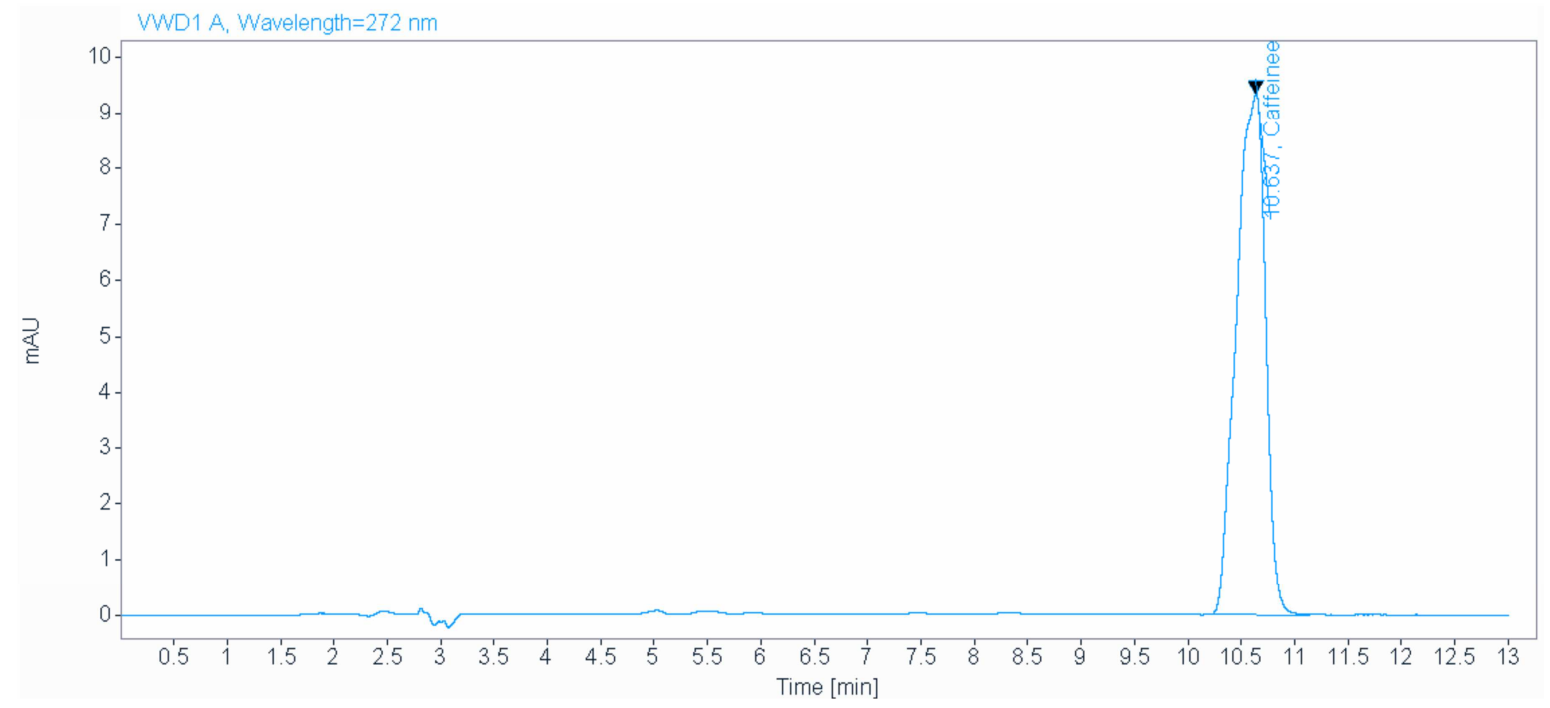

Appendix I: Chromatogram of Caffeine of Gida Ayana Coffee Sample (Spiked)

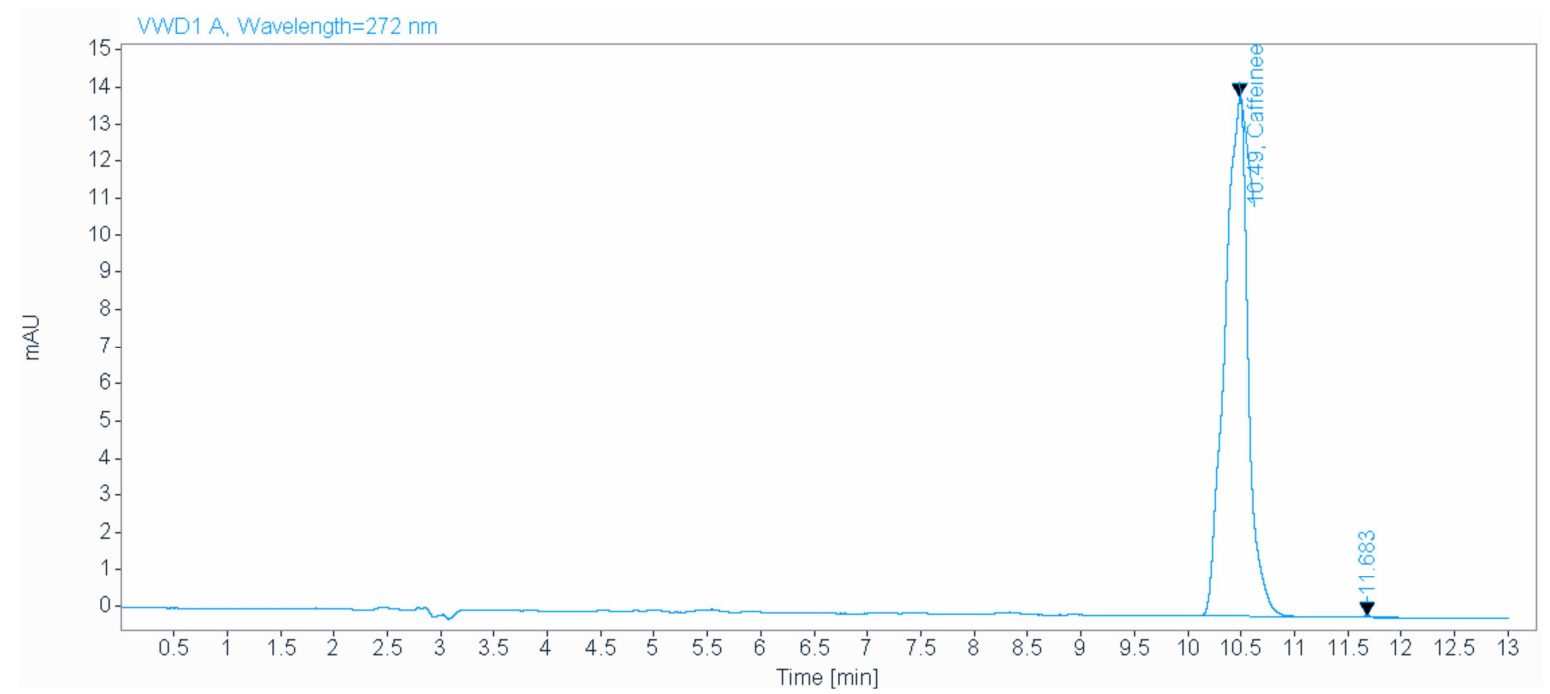

Appendix J: Chromatogram of Caffeine of Sasiga Coffee Sample (Duplicated)

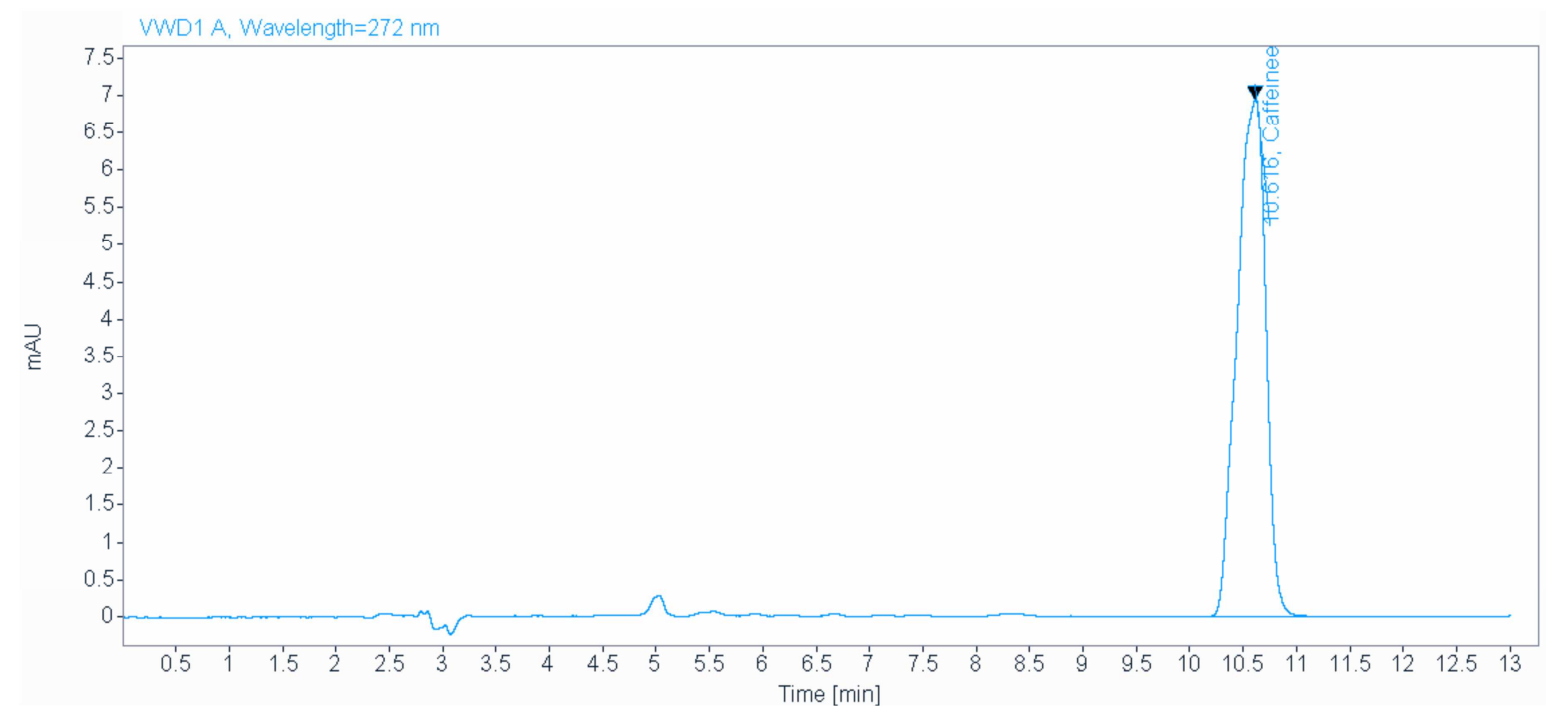




\section{References}

[1] Murthy, P. S. \& Naidu, M. M. Sustainable management of coffee industry by-products and value addition. Resources, Conservation and Recycling, 2012, 66, 45-58.

[2] Yonas Belete, Bayetta Belachew \& Chemeda Fininsa. Evaluation of bean qualities of indigenous Arabica Coffee genotypes across different environments. Journal of Plant Breeding and Crop Science, 2014, 6, 135-143.

[3] Mussattoa, I., Livia, M., Carneirob, P. A. \& Teixeira, A. A study on chemical constituents and sugar extraction from spent coffee grounds. Carbohydrate Polymers, 2011, 83, 368374.

[4] Gomez-Rui, J. N., David, S. L. \& Jennifer, M. In vitro antioxidant activity of coffee compounds and their metabolites Journal of Agriculture and Food Chemistry, 2007, 55, 69626969.

[5] Nuhu, A. Bioactive micronutrients in coffee: Recent analytical approaches for characterization and quantification. ISRN Nutrition. Retrieved from http://dx.doi.org/10.1155/2014/384230, 2014.

[6] Alonso-Salces, M., Francesca, S., Fabiano, R. \& Berger, K. Botanical and geographical characterization of green coffee (Coffea arabica and Coffea canephora): Chemometric evaluation of phenolic and methylxanthine contents. Journal of Agriculture and Food Chemistry, 2009, 57, 4224-4235.

[7] Shishov, A., Volodina, N., Nechaeva, D., Gagarinova, S., \& Bulatov, A. An automated homogeneous liquid-liquid microextraction based on deep eutectic solvent for the HPLCUV determination of caffeine in beverages. Microchemical Journal, 2019, 144, 469-473.

[8] Vuong, V. \& Roach, D. Caffeine in green tea. Its removal and isolation. Separation \& Purification Reviews, 2014, 43, 155174.

[9] Oba, S., Nagata, C., Nakamura, K., Fujii, K., Kawachi, T., Takatsuka, N. \& Hiroyuki S. Consumption of coffee, green tea oolong tea, black tea, chocolate snacks and the caffeine content in relation to risk of diabetes in Japanese men and women. British Journal of Nutrition, 2010, 103, 453-459.

[10] Bhupathiraju, S N., Pan, A., Vasanti, S., Manson, E., Willett, C., Dam, M. \& Frank, B Caffeinated and caffeine-free beverages and risk of type 2 diabetes. American Journal of Clinical Nutrition, 2013, 97, 163-174.

[11] Mazzafera, P. \& Silvarolla, M. Caffeine content variation in single green Arabica coffee seeds. Seed Science Research, 2010, 20, 163-167.

[12] Tello, J., Viguera, M. \& Calvo, L. Extraction of caffeine from Robusta coffee (Coffea canephora vs Robusta) husks using supercritical carbon dioxide. The Journal of Supercritical Fluids, 2011, 59, 53-60.

[13] Nawrot, P., Jordan, S., Eastwood, J., Rotstein, J., Hugenholtz, A. \& Feeley, M. Effects of caffeine on human health. Food Additives and Contaminants, 2003, 20, 1-30.

[14] Tsvetkova, B. G., Kostova, B. D., Rachev, D. R., Peikova, L. T. \& Pencheva, I. P. HPLC assay and stability studies of tablets containing paracetamol and caffeine. International Journal of Pharmaceutical Sciences Review and Research, 2013, 18, 138-142.

[15] Rodrigues, N. P. \& Bragagnolo, N. Identification and quantification of bioactive compounds in coffee brews by HPLC-DAD-MSn. Journal of Food Composition and Analysis, 2013, 32, 105-115.

[16] Magalhaes, L. M., Sandia, M., Marcela, S., Joa, A. L. \& Pascoa, N. M. Rapid assessment of bioactive phenolics and methylxanthines in spent coffee grounds by FTNIRspectroscopy. Talanta, 2016, 143, 460-467.

[17] Vichare, V., Mujgond, P., Tambe, V. \& Dhole, S. N. Simultaneous spectrophotometric determination of paracetamol and caffeine in tablet formulation. International Journal of PharmTech Research, 2010, 2, 2512-2516.

[18] Tautua, A. W., Bamidele, M. \& Diepreye, E. R. Ultra-violet spectrophotometric determination of caffeine in soft and energy drinks available in Yenagoa, Nigeria. Advance Journal of Food Science and Technology, 2014, 6, 155-158.

[19] Rotko, T. K. \& Bęczkowska, I. Nafion covered lead film electrode for the voltammetric determination of caffeine in beverage samples and pharmaceutical formulations. Food Chemistry, 2015, 172, 24-29.

[20] Maidon, B., Atikah, O. \& Hermen, S. Study of various solvents for caffeine determination using UV-Vis Spectrophotometeric method. Journal of Applied Sciences Research, 2012, 8, 2439-2442.

[21] Navarra, G., Moschetti, M., Guarrasi, V., Mangione, M. R., Militello, V. \& Leone. M. Simultaneous determination of caffeine and chlorogenic acids in green coffee by UV-Vis Spectroscopy. Journal of chemistry. Retrieved from https://doi.org/10.1155/2017/6435086, 2017.

[22] Mulu Hagos, Mesfin Redi-Abshiro, Bhagwan Singh Chandravanshi, Estifanos Ele Ahmed M. Mohammed \& Hassen Mamo. The correlation between caffeine contents of green coffee beans and altitudes of the coffee plants grown in South West Ethiopia. Bulletin Chemical Society of Ethiopia, 2018, 32, 13-25.

[23] Abebe Belay, Kassahun Ture, Mesfin Redi \& Araya Asfaw. Measurement of caffeine in coffee beans with UV-Vis spectrophotometry. Food Chemistry, 2008, 108, 310-315.

[24] Shrivastava, A. \& Gupta, V. B. Methods for the determination of limit of detection and limit of quantitation of the Analytical methods. Chronicles of Young Scientists, 2011, 2, 21-25.

[25] Hecimovic, I., Cvitanovic, B. A., Horzic, D. \& Komes. D. Comparative study of polyphenols and caffeine in different coffee varieties affected by the degree of roasting. Food Chemistry, 2011, 129, 991-1000.

[26] Hagos Yisak, Mesfin Redi-Abshiro \& Bhagwan Singh Chandravanshi. Selective determination of caffeine and trigonelline in aqueous extract of green coffee beans by FTMIR-ATR spectroscopy. Vibrational Spectroscopy, 2018, 97, 33-38.

[27] Gichimu, B. M., Gichuru, E. K., Mamati, G. \& Nyende, A. B. Biochemical composition within Coffea arabica cv. Ruiru 11 and its relationship with cup quality. Journal of Food Research, 2014, 3, 31-44. 
[28] Sahar, A., Maryam, S. \& Parisa, Z. Comparative Study of Mineral Elements and Caffeine in Imported Coffee Varieties Affected by the Degree of Roasting by HPLC Analysis. Journal of Chemical and Pharmaceutical Research, 2016, 8, 111-116.

[29] Belete Tewabe Gebeyehu \& Solomon Libsu Bikila. Determination of caffeine content and antioxidant activity of coffee. American Journal of Applied Chemistry, 2015, 3, 6976.

[30] Ephrem Demissie, Girma Woyessa \& Arayaselassie Abebe. $\mathrm{UV}-\mathrm{V}$ is spectrophotometery determination of caffeine in green coffee beans from Hararghe, Ethiopia, using BeerLambert's law and integrated absorption coefficient techniques. Scientific Study \& Research Chemistry \&
Chemical Engineering, Biotechnology, Food Industry, 2016, 17, 109-123.

[31] Maria, B. S., Paulo, M. \& Marinez, A. L. Caffeine content of Ethiopian Coffea arabica beans. Genetics and Molecular Biology, 2000, 23, 213-215.

[32] Legesse Adane, Mesfine Shiferaw \& Israel Alemayehu. Determination of Caffeine Content of Bale Coffee Using HPLC Analysis. Food Science and Quality Management, 2018, 73, 23-32.

[33] Dessalegn, Y., Labuscagne, M. T., Osthoff, G. \& Herselman, L. Variation of green bean caffeine, chlorogenic acids, sucrose and trigolline contents among Ethiopian Arabica coffee accessions. Ethiopian Journal of Science, 2008, 30, 77-82. 